\title{
KONSEP BILINGUALISME DAN PEMBELAJARAN BAHASA INDONESIA BAGI PENUTUR ASING
}

\author{
Edy Subali
}

\begin{abstract}
ABSTRAK
Artikel ini berjudul "Konsep Bilingualisme dan Pembelajaran BIPA". Pertanyaannya adalah bagaimana konsep bilingualisme dapat membantu mempermudah dan memperlancar proses pembelajaran BIPA? Konsep pada dasarnya merupakan prinsip atau asas yang dapat menjadi dasar berfikir atau bertindak. Bagaimana pengajar dan pembelajar BIPA memanfaatkan dan menerapkan konsep bilingualisme kepada pembelajar penutur asing yang majemuk: B1-nya majemuk, latar sosial budayanya majemuk, tujuan mereka belajar B2 bahasa Indonesia juga majemuk. Konsep atau prinsip bilingualisme yang dapat dimanfaatkan sebagai kerangka dasar, misalnya: hipotesis pemerolehan versus pembelajaran, hipotesis monitor, hipotesis saringan afektif, hipotesis urutan alamiah dan hipotesis masukan, dan teori akulturasi. Selain itu, silabus pembelajarannya mempertimbangkan kemajemukan pembelajar BIPA. Bahan ajar pembelajaran BIPA pun perlu memperhatikan tujuan mereka atau penutur asing belajar bahasa Indonesia, garadasi kesulitan bahan ajar, variasi bahan ajar, konteks, dan integrasi bahan ajarnya. Sedangkan prinsip-prinsip pembelajaran BIPA yang perlu diperhatikan misalnya, aspek lintas budaya pembelajar dan pengajar, dan karakteristik pembelajar sebagai orang yang berkategori dewasa.
\end{abstract}

Kata kunci: konsep bilingualisme, BIPA, akulturasi, pemerolehan, pembelajaran

Globalisasi merupakan keniscayaan. Kemajuan ilmu pengetahuan dan teknologi, pertumbuhan ekonomi dan stabilitas sosial, politik nasional, regional dan internasional sangat berpengaruh terhadap percepatan prores globalisasi. Akibat lanjutannya: (1) ruang tempat manusia berada, berfikir dan bertindak cenderung semakin melebar dan meluas melintasi batas-batas wilayah negara, (2) saling ketergantungan dan kerja sama antarnegara atau antarbangsa dalam berbagai bidang dianggap penting dan mendesak, (3) mobilitas barang, modal dan orang dengan beragam tujuan (wisata, perdagangan, pendidikan, politik) tidak bisa dihindari, (4) globalisasi membawa manusia pada globalisme, yaitu suatu pola pikir atau paham yang memperlakukan seluruh dunia sebagai lingkungan yang layak diperhitungkan, bukan saja dari aspek ekonomi, politik, sosial, budaya dan keamanan, tetapi juga aspek pendidikan dan pembelajaran, termasuk pembelajaran bahasa, baik bahasa pertama (B1) maupun bahasa kedua (B2), bahasa ketiga (B3) dan seterusnya. 
Globalisasi menumbuhsuburkan semangat masyarakat manusia di dunia ini untuk menjadi bilingualisme dan multilingualisme. Manusia di dunia dalam era globalisasi ini, termasuk manusia Indonesia merasa tidak cukup jika hanya menguasai bahasa daerah atau bahasa ibunya (B1) dan bahasa nasionalnya (B2). Mereka, kita, dan semua manusia normal di dunia ini semakin menganggap penting menguasai bahasa asing (BA). Oleh karenanya, tumbuh pula lembaga-lembaga pendidikan, baik formal maupun nonformal yang memfasilitasi proses pembelajaran bahasa asing. Masyarakat di dunia ini mempersepsi bahwa bahasa asing merupakan media komunikasi dan transformasi yang sangat penting bagi keperluan pergaulan dunia yang cenderung sudah mengglobal sehingga sangatlah masuk akal apabila jumlah pembelajar dan pemakai bahasa asing cenderung terus semakin bertambah banyak.

Bahasa asing adalah bahasa yang dikuasai oleh bahasawan, biasanya melalui pendidikan formal, dan yang secara sosiokultural tidak dianggap bahasanya sendiri (Kridalaksana, 1984:20). Pertanyaannya, apakah bahasa Indonesia dapat diposisikan sebagai bahasa asing? Siapa yang cenderung memposisikan bahasa Indonesia sebagai bahasa asing? Bagaimana kecenderungan pertumbuhan jumlah pembelajar asing (bangsa asing) terhadap bahasa Indonesia? Apakah cenderung semakin bertambah banyak atau sebaliknya? Apa faktor atau variabel yang mempengaruhi jumlah pembelajar bahasa Indonesia sebagai bahasa asing bertambah banyak atau sebaliknya?

Bahasa Indonesia dapat berposisi sebagai bahasa asing jika pembelajar atau pemakainya warga negara asing. Faktor atau variabel yang mempengaruhi apakah jumlah peminat atau pembelajarnya bertambah banyak atau sebaliknya sangatlah kompleks. A. Soegihartono dalam Prosiding The 4th International Conference on Indonesian Studies: "Unity, Diversity and Future" mengatakan bahwa republik Indonesia merupakan negara kepulauan yang membentang luas dari Aceh hingga Papua. Luas perairannya mencapai 93 ribu km2 dengan 17.504 pulau tersebar di dalamnya. Jumlah penduduk hingga saat ini berkisar 270 juta jiwa. Ditinjau dari segi geografis dan demografisnya, Indonesia memiliki potensi besar di berbagai bidang (politik, ekonomi, sosial, budaya dan hankam) sehingga memiliki daya tarik bagi 
masyarakat internasional. Potensi keragaman Sumber Daya Alam (SDA) Indonesia, Sumber Daya Manusia (SDM) dan seni budayanya yang beragam akan memfasilitasi bahasa Indonesia untuk semakin dipelajari oleh masyarakat dunia. Selain itu, penguasaan bahasa Indonesia bagi mereka sudah menjadi kebutuhan diplomasi sehingga dapat menjamin keberlangsungan interaksi mutualisme selanjutnya.

Bali misalnya, banyak didatangi wisatawan asing dari berbagai negara dengan latar belakang sosial-budaya yang beragam pula. Bagi mereka atau wisatawan tersebut menjadi pembelajar BIPA adalah sangat penting untuk keperluan interaksi dan komunikasi dengan masyarakat Bali, baik dalam hal sistem sosialnya maupun sistem ekonomi dan budayanya. Jadi, faktor yang dapat menjadi variabel penting apakah pembelajar BIPA bertambah banyak atau sebaliknya adalah faktor sosial, budaya, ekonomi, pilitik, pendidikan atau iptek, demografi, geografi dan hankam. Hasil penelitian Ovi Soviaty Rivai dkk. (2010) menyebutkan bahwa tidak kurang dari 36 negara yang telah mengajarkan BIPA. Selain dilakukan di KBRI dan beberapa tempat khusus, juga diajarkan di sejumlah universitas. Di Amerika Serikat terdapat 9 universitas yang mengajarkan bahasa Indonesia. Di Jerman ada 10 univeritas, di Italia lebih dari 6 universitas dan di Jepang ada 26 universitas. Di Australia, bahasa Indonesia selain diajarkan di 27 universitas juga diajarkan di beberapa sekolah menengah.

Pembelajaran BIPA bertujuan agar mereka memiliki kemampuan menggunakan bahasa Indonesia untuk bermacam-macam tujuan: untuk wisata, studi atau pendidikan di Indonesia, politik, sosial dan lain sebagainya. Pembelajar BIPA tentu berharap dapat memiliki kemampuan dan ketrampilan menggunakan bahasa Indonesia lisan dan tertulis. Pembelajaran BIPA, entah disadari atau tidak, dapat juga berfungsi sebagai media pemberi informasi budaya Indonesia kepada penutur asing karena berbahasa berarti mengekspresikan nilai-nilai budaya masyarakat pemiliknya. Oleh karena itu, keberhasilan pembelajaran BIPA tidak akan optimal apabila tidak menyertakan aspek-aspek sosial budaya yang berlaku dalam masyarakat bahasa yang dipelajari. 
Ada kecenderungan terjadi peningkatan jumlah peminat atau jumlah pembelajar BIPA di dalam negeri dan luar negeri. Mereka ingin menjadi bilingual atau multilingual dengan bahasa Indonesia sebagai bahasa kedua atau ketiganya. Mereka berasal dari beberapa negara sehingga bukan saja bahasa pertama para pembelajar BIPA yang beragam, tetapi latar belakang sosial budaya, tujuan belajar bahasa Indonesia serta usia pembelajar BIPA juga bisa beragam. Mereka ingin menjadi pembelajar BIPA langsung di Indonesia, tetapi ada juga yang belajar BIPA di negaranya sendiri. Pertanyaannya:

1) Bagaimana menjelaskan bahwa konsep bilingualisme dapat membantu memperlancar proses pembelajaran BIPA?

2) Apa yang harus disiapkan untuk membantu memperlancar proses pembelajaran BIPA?

\section{BILINGUALISME}

Artikel ini berjudul "Konsep Bilingualisme dan Pembelajaran BIPA". Bagaimana konsep bilingualisme dapat membangtu mempermudah atau memperlancar proses pembelajaran BIPA? Bagaimana konsep bilingualisme dapat membantu penutur asing menjadi bilingual atau multilingual dengan bahasa Indonesia sebagai bahasa kedua atau ketiganya. Apa konsep atau teori bilingualisme yang bisa dimanfaatkan untuk memperlancar dan mempercepat proses pembelajaran BIPA? Beberapa teori dalam konsep bilingualisme yang bisa menjadi kerangka acuan pembelajaran BIPA, yaitu (1) teori akulturasi dari Schuman, (2) dan teori pemerolehan B2/Asing.

Premis pokok teori akulturasi dari Schuman (dalam Fuad Abdul Hamied, 1989:246) adalah bahwa pembelajaran BIPA hanyalah satu aspek dari proses akulturasi. Tingkat akulturasi si pembelajar, yakni penutur asing terhadap budaya masyarakat bahasa sasaran (budaya bangsa Indonesia) akan mengontrol tingkat keberhasilannya dalam belajar BIPA. Semakin ada kemiripan antara budaya si pembelajar BIPA dengan budaya kelompok bahasa sasaran, yaitu budaya bangsa Indonesia maka akan mempermudah dan memperlancar keberhasilan pembelajar BIPA. Demikian juga sebaliknya, semakin jauh berbeda antara budaya pembelajar 
BIPA dengan budaya bangsa Indonesia maka semakin tidak mudah untuk cepat berhasil dalam pembelajaran BIPA karena saringan afeksi pembelajar BIPA bisa menjadi faktor kendalanya sehingga kejutan budaya dan kejutan bahasa relatif membuat pembelajar BIPA perlu waktu agak lama untuk melepaskan beban-beban psikologisnya dalam proses pembelajarannya.

Dari perspektif yang lain, jika pembelajar BIPA memiliki cukup bekal pengetahuan dan pemahaman tentang budaya masyarakat bahasa target (budaya bangsa Indonesia) maka mereka akan memiliki modal untuk berinteraksi secara efektif dengan masyarakat bahasa target. Interaksi efektif antara pembelajar BIPA dan masyarakat bahasa target akan memfasilitasi atau menciptakan atmosfer hubungan yang kondusif sehingga interaksi yang berarti praktik berbahasa Indonesia akan berlangsung secara alamiah dan berkelanjutan. Sebaliknya, tanpa cukup bekal tentang sistem sosial budaya masyarakat bahasa target maka kegiatan berinteraksi antara kedua belah pihak cenderung kurang kondusif sehingga interaksi yang berarti praktik bertutur dengan bahasa Indonesia juga akan mudah kaku karena pembelajar BIPA masih memiliki beban-beban psikologis (takut, malu, khawatir) untuk bertutur secara leluasa dan wajar.

Selain akulturasi, faktor jarak sosial dan kejiwaan antara pembelajar BIPA dengan budaya bahasa bangsa Indonesia juga akan mempengaruhi tingkat keberhasilan pembelajaran BIPA. Jauh dekatnya jarak sosial dan budaya dapat menyebabkan timbulnya:

a) kejutan bahasa, yang diakibatkan adanya pengalaman buruk pembelajar dalam menggunakan bahasa target;

b) kejutan budaya; pembelajar mudah timbul keraguan atau kekhawatiran bahkan ketakutan sebagai akibat dari perbedaan budaya pembelajar BIPA dengan budaya masyarakat bahasa target; dan

c) motivasi atau dorongan kuat atau lemah yang dimiliki pembetajar BIPA untuk menguasai bahasa target.

Jadi, dapat disimpulkan bahwa makin memiliki kemampuan bagi pembelajar BIPA dalam mengadaptasi budaya masyarakat bahasa target maka makin besar kemungkinan untuk cepat berhasil mernpelajari dan menguasai bahasa target. 
Sebaliknya, kejutan bahasa dan kejutan budaya akan menjadi kendala dalam mempelajari dan menguasai bahasa target jika pembelajar tidak cukup bekal pengetahuan sosial budaya masyarakat bahasa target sehingga peluang untuk beradaptasi dan berintaraksi dengan masyarakat bahasa target kurang bebas. Berdasarkan kenyataan tersebut maka pembelajaran BIPA perlu didukung juga oleh pembelajaran sosial dan budaya bangsa Indonesia agar pembelajar BIPA dapat menempatkan dirinya sesuai dengan norma-norma sistem sosial budaya masyarakat bangsa Indonesia ketika proses interaksi social antara pembelajar BIPA dengan masyarakat Indonesia berlangsung.

Selain dengan pendekatan budaya atau akulturasi, juga terdapat lima hipotesis sebagaimana yang dikemukakan oleh Krashen dan Terrel untuk menjelaskan proses pembelajaran BIPA, yaitu hipotesis pemerolehan-pembelajaran, hipotesis urutan alamiah, hipotesis pemantau, hipotesis masukan, dan hipotesis saringan afektif. (Sri Utari Subyakto-Nababan, 1992:87-93). Tulisan ini hanya memfokuskan pada tiga saja, yaitu hipotesis pemerolehan-pembelajaran, hipotesis pemantau, hipotesis saringan afektif.

\section{Hipotesis Pemerolehan-pembelajaran}

Berdasarkan pandangan Krashen dan Terrell, pembelajaran BIPA dapat menggunakan dua strategi untuk mencapai keberhasilan dalam pembelajaran BIPA, yaitu dengan strategi pemerolehan (acquisition) dan dengan strategi pembelajaran (learning). Strategi pemerolehan, menurut Krashen adalah proses penguasaan bahasa yang identik dengan cara anak mengembangkan kemampuannya dalam menguasai bahasa pertama atau bahasa ibunya. Anak menguasai bahasa pertama atau ibunya melalui proses yang tidak disadari. $\mathrm{Si}$ anak hanya terbiasa mengekspresikan keadaan jiwanya dalam beranekaragam bentuk. Misalnya, berbentuk tangisan, celotehan, baba, mama dan seterusnya hingga ia memiliki kesadaran untuk berkontak atau berinteraksi dengan lingkungan yang secara emosional dekat (ibu-bapaknya) untuk memenuhi kebutuhannya. Si anak tidak ada niat belajar berbahasa apalagi pembelajaran yang bersifat formal-klasikal. ' 
Berdasarkan konsep pemerolehan maka pembelajar BIPA akan menguasai bahasa target, yaitu bahasa Indonesia hanya dengan secara langsung berinteraksi dan berkomunikasi dengan orang Indonesia dengan media bahasa Indonesia. Komunikasi tersebut bukan dengan tujuan belajar bahasa Indonesia, akan tetapi untuk kebutuhan hidupnya. Kegiatan berinteraksi dan berkomunikasi langsung dan wajar tersebut perlu dilakukan berkali-kali tanpa perlu merasa takut ditertawai mitranya hanya karena bahasa yang digunakan tidak baik dan tidak benar. Anak balita dapat dengan mudah dan lancar menguasai bahasa ibu/pertamanya karena ia berani langsung berkomunikasi. Anak balita memperoleh kemampuan berbahasa bukan karena secara sengaja dan disadari untuk belajar berbahasa. Akan tetapi, karena dia butuh dua hal, yaitu untuk mengekspresikan perasaan tertentu, misalnya dingin, hausa tau lapar kemudian menangis. Sang ibu biasanya berusaha untuk mengerti apa maksudnya. Kontak semacam itu tentu akan berulang-ulang sehingga memungkinkan untuk terbentuknya ikatan batin dan bentuk-bentuk komunikasi tertentu antara anak dan ibunya. Kedua, anak secara sengaja dan sadar berkontak dengan orang lain untuk keperluan hidupnya: minta makan, minum, mainan dan semacamnya.

Pembelajaran BIPA dengan berdasar pada konsep pemerolehan seakan-akan mewajibkan pembelajar untuk mengekspresikan dan menuturkan kebutuhan hidupnya secara berani dan terbuka kepada lawan tuturnya. Kebutuhan hidupnya itu pada awalnya bisa dituturkan dengan disertai bahasa isyarat. Lawan atau mitra tuturnya tentu berusaha untuk memahami apa maksudnya, kemudian memberikan respon balik dengan menggunakan bahasa Indonesia. Dengan kegiatan seperti itu dan dilakukan berulang-ulang maka piranti bahasa yang oleh Chomsky diistilahkan Language Acquisition Devide (LAD) yang dimiliki setiap manusia akan semakin "terasah" atau "terasuh". Dengan bantuan piranti tersebut maka proses pembelajaran BIPA dapat mempercepat kemampuannya menguasai bahasa target.

Dengan berdasar pada konsep pemerolehan dalam proses pembelajaran BIPA maka pertanyaannya: apakah kaidah bahasa target juga diperoleh secara tidak disadari atau lebih tepat diperoleh secara implisit? Jawabannya adalah pembelajar cenderung dapat menggunakan ucapan atau lafal yang benar dan ucapan yang salah, 
penggunaan kata yang benar dan penggunaan kata yang salah. Akan tetapi, pembelajar biasanya tidak serta merta dapat menjelaskan mengapa benar dan mengapa salah, kaidah apa atau yang mana yang dilanggar. Manusia termasuk makhluk yang memiliki kemampuan mengevaluasi dan mengontrol pengetahuan dan tindakannya sendiri, termasuk tindakan berbahasa. Setiap manusia pembelajar bahasa cenderung dapat mengontrol penggunaan kata-kata yang salah, tidak sopan, ucapannya yang tidak tepat, struktur kalimat salah, entah karena ditegur atau diberitahukan oleh lawan tuturnya atau karena kemampuannya untuk mengevalusinya. Dengan demikian, kegiatan pembelajaran bahasa, apalagi bagi pembelajar BIPA pasti melalui proses: belajar bahasa dengan langsung alami atau praktik, evaluasi, menyadari adanya kesalahan, pembetulan, praktik berbahasa lagi, dan seterusnya secara berulang dan berkelanjutan hingga kesalahan-kesalahan atau lebih tepat disebut kehilafan berbahasa semakin berkurang.

Jika konsep pemerolehan bahasa berdasar pada ketidaksadaran atau ketidaksengajaan, tahu-tahu bisa berbahasa maka konsep pembelajaran bahasa justru berdasar pada proses pembelajaran yag disengaja dan memang disadari untuk belajar berbahasa. Jadi, pembelajar BIPA mengembangkan kompetensi bahasa Indonesia dengan sengaja belajar (learning) pada gurunya. Para pembelajar BIPA secara sengaja atau sadar belajar kaidah-kaidah bahasa target, misalnya lafal, diksi dan kaidah tatabahasanya. Konsep penguasaan bahasa target diupayakan seperti pembelajaran bahasa konvensional di sekolah-sekolah.

\section{Hipotesis Manitor}

Menurut Krashen, konsep penguasaan suatu bahasa secara sengaja dan sadar, sebagaimana pembelajaran bahasa formal dan konvensional di sekolah-sekolah hanya mempunyai fungsi yang sangat terbatas. Hasil pembelajaran secara sengaja dan formal tersebut hanya digunakan untuk memantau, memonitor dan menyunting penguasaan bahasa yang dicapai melalui konsep pemerolehan. Ketrampilan berbicara, termasuk berbahasa Indonesia pada hakikatnya melalui konsep pemerolehan, bukan dengan konsep pembelajaran. Pengetahuan formal tentang bahasa target, yaitu bahasa Indonesia, termasuk kaidah-kaidah tatabahasa yang 
diperoleh melalui konsep pembelajaran hanya berfungsi sebagai pengecek atau pemonitor saja.

Mekanisme penggunaan monitor oleh pembelajar bahasa dapat mempengaruhi kelancaran dan kualitas kemampuan menguasai bahasa target. Jika pembelajar bahasa menggunakan monitor terlalu tinggi karena bertujuan agar dalam menggunakan bahasa target tampak baik dan benar maka proses pembelajaran dan kualitas penggunaan bahasa target biasanya kaku, kurang lancar dan tersendatsendat. Pembelajar bahasa dengan tuntutan kemampuan berbahasa target dengan kebenaran tinggi ini biasanya disebut overusers. Ada pula pembelajar yang tuntutan terlalu rendah terhadap kebenaran dan kebaikan penggunaan bahasa target, (biasanya disebut"underusers") sehingga pembelajar bahasa hanya menggunakan monitor apa adanya, tanpa dihantui oleh kaidah-kaidah bahasa yang ditahui atau yang telah dipelajarinya. Pembelajar semacam itu cenderung lambat dalam penguasaan ketrampilan bahasa target. Pembelajar bahasa yang ideal adalah mereka yang menggunakan hasil pembelajaran formal dan sengaja sebagai pelengkap hasil pemerolehannya. Mereka memanfaatkan monitor (kaidah bahasa yang diketahui dari pembalajaran sadar/formal) hanya sewajarnya saja tanpa mengganggu praktik dalam menggunakan bahasa target. Mereka biasanya disebut pembelajar atau pemakai yang optimal atau "optimal users".

Penggunaan monitor (kaidah bahasa hasil belajar formal) ketika memakai bahasa target dalam kegiatan berkomunikasi dalam kehidupan memang dapat membantu menyempurnakan bentuk-bentuk bahasa target. Lafal yang salah dapat dimonitor kemudian dibetulkan, diksi yang tidak baik dapat dipantau dan dipilihkan diksi yang baik. Demikian pula pemakaian tatabahasanya juga dapat dicek kebenarannya dan kemudian dapat diperbaiki jika terdapat kesalahan tatabahasa.

\section{Hipotesis Saringan Afektif}

Saringan afeksi berkaitan dengan sikap pembelajar bahasa. Apakah pembelajar bahasa cenderung bersikap positif atau justru lebih sering bersikap negatif ketika proses pembelajaran bahasa (BIPA) berlangsung, baik melalui konsep pemerolehan maupun melalui konsep pembelajaran. Pembelajar bahasa dikatakan 
bersikap positif apabila dalam proses pembelajaran bahasa target berdasar pada rasa percaya diri dan motivasi tinggi untuk memiliki kemampuan menggunakan bahasa target. Percaya diri berarti keraguan, kehawatiran, ketakutan ketika proses pembelajaran bahasa target berlangsung relatif rendah. Contoh yang dapat dipakai sebagai model pembelajar bahasa yang digolongkan bertumpu pada sikap positif dan motivasi tinggi adalah anak balita (bawah lima tahun) ketika belajar bahasa pertama atau bahasa ibu. Anak balita ketika belajar bahasa pertama tersebut tampak aktif dan mandiri. Keraguan, kekhawatiran dan ketakutan ketika berinteraksi dan berkomunikasi dengan orang-orang di sekitarnya benar-benar tanpa saringan afeksi. Ketika anak balita berkomunikasi dengan mitranya (orang tuanya atau yang lain) cenderung bersikap wajar, tenang walaupun banyak sekali kesalahan-kesalahannya, baik pengucapan, diksi maupun struktur bahasanya. Akan tetapi, mereka secara aktif dan mandiri belajar memperbaiki kesalahan-kesalahan tersebut.

Yang sangat penting untuk diperhatikan oleh pembelajar BIPA adalah keberanian untuk langsung menggunakan bahasa target dalam kehidupan seharihari. Keberanian berarti kemampuan melepaskan diri dari beban-beban psikologis, seperti ketegangan dan kekhawatiran. Berani berarti aktif berlatih berkomunikasi dan sadar bahwa menerima masukan, perbaikan dan mitra juga sangat penting.

Yang perlu disiapkan untuk membantu memperlancar proses pembelajaran BIPA adalah terkait dengan input atau masukan, proses dan keluaran. Pembelajaran BIPA merupakan suatu sistem. Berarti ada masukan, ada proses dan ada keluaran. Pada unsur masukan, pembelajar BIPA berasal dari berbagai negara sehingga B1nya bermacam-macam, tujuan mereka belajar bahasa Indonesia pun bisa berbedabeda pula, bahkan usia dan latar belakang sosial budaya pembelajar BIPA juga bisa bermacam-macam. Dengan input atau masukan yang beragam maka proses pembelajaran BIPA memerlukan guru, pengajar, fasilitator dan motivator yang tidak hanya berbekal pengetahuan kebahasaan dan pengatahuan didaktik dan metodik saja, tetapi juga perlu bekal pengetahuan komunikasi antarbudaya. Selain itu, yang perlu disiapkan juga adalah silabus. Di dalamnya memuat tentang tujuan pembelajar BIPA, gradasi kesulitan bahan ajar BIPA, variasi bahan ajar dan konteks bahan ajar serta integrasi bahan ajar. 
Pembelajar BIPA yang bertujuan berwisata dengan yang bertujuan studi lanjut perlu disiapkan bahan ajar yang berbeda. Jika tujuan pembelajar BIPA adalah agar nyaman dan aman berwisata maka bahan ajarnya bisa berupa nama-nama tempat wisata, petunjuk arah menuju tempat wisata, menu makanan dan bahan lain yang relevan dengan tempat wisata. Jika tujuannya bekerja maka bahan ajarnya bias surat perjanjian kerja, surat-menyurat dan lain-lainnya yang relevan.

Prinsip gradasi tingkat kesulitan bahan ajar pun juga perlu memperhatikan apakah pembelajar BIPA berada pada level dasar, menengah atau mahir? Bahan ajar yang terlalu sulit atau terlalu mudah akan berimbas pada motivasi pembelajar BIPA. Oleh karenanya, bahan ajarnya disusun berdasarkan tingkat kesulitan. Misalnya, bahan ajar bergerak dari mudah ke sulit dan dari kongkret ke abstrak.

Prinsip berikutnya adalah variatif. Bahan ajar yang tidak bervariasi akan menimbulkan kejenuhan. Contohnya, pembelajaran membaca. Bahannya perlu bervariasi, misalnya wacana narasi, deskripsi, persuasi. Wacana iklan, menu makanan, pertanian, seni tari, gamelan dan wacana lainnya yang relevan. Yang penting adalah isi wacana harus sesuai dengan tema yang telah ditentukan. Misalnya, tema jual-beli maka wacana yang menjadi bahan ajarnya dapat berupa dialog antara pedagang dan pembelinya.

Prinsip konteks bahan ajar. Bahan ajar perlu dikaitkan dengan konteks agar bermakna. Oleh karenanya pengembangan bahan ajar harus ada tema yang akan mengikat keseluruhan bahan ajar. Tema-tema pun harus disesuaikan dengan tingkat kompetensi pembelajarnya. Tema sebaiknya dari yang kongkret ke yang abstrak. Pemberian konteks dapat memudahkan pengajar untuk mengintegrasikan berbagai materi. Berikut ini contoh tema-tema yang dapat diberikan untuk tingkat dasar/pemula, tingkat menengah dan tingkat mahir. Ada perbedaan tentang tingkat kekongkretan dan variasi temanya. 


\begin{tabular}{|l|l|l|}
\hline \multicolumn{1}{|c|}{ TINGKAT DASAR } & \multicolumn{1}{|c|}{$\begin{array}{c}\text { TINGKAT } \\
\text { MENENGAH }\end{array}$} & \multicolumn{1}{c|}{ TINGKAT MAHIR } \\
\hline Perkenalan & Keluarga & Gaya hidup \\
\hline Keluarga & Jenjang pendidikan & Kesenian Indonesia \\
\hline Bemo & Angkutan & Transportasi \\
\hline Profesi & Bencana alam & Ramah lingkungan \\
\hline
\end{tabular}

Variasi tema di atas, selain dapat membantu pembelajar memahami bahan ajar juga dapat membantu pembelajar asing memahami realitas kehidupan masyarakat Indonesia. Pembelajar asing yang belajar di Indonesia tentu akan melakukan kegiatan berkenalan dengan orang lain di Indonesia, bertetangga dan bepergian. Melalui tema-tema tersebut maka pembelajar dapat memahami apa yang harus diucapkan ketika berkenalan, bertetangga dan bepergian dengan alat transportasi.

Prinsip terakhir adalah integrasi bahan ajar. Belajar berbahasa berbeda dengan belajar bahasa. Belajar berbahasa mengacu pada empat keterampilan berbahasa: menyimak, berbicara, membaca dan menulis. Dalam belajar empat keterampilan tersebut tentu dibutuhkan pengetahuan tentang fonologi, morfologi, sintaksis dan semantik bahasa yang dipelajari. Selain itu, penting pula dipelajari adalah budaya masyarakat pemakai bahasa yang menjadi targetnya. Kalau BIPA berarti kebudayaan Indonesia. Dengan demikian pengelola dan pengajar BIPA perlu dapat mengintegrasikan tiga hal tersebut dalam pengembangan bahan ajar. Ketidaktahuan pembelajar pada budaya Indonesia dapat menimbulkan kejut budaya dan salah paham. Ketidaktahuan pembelajar tentang tata bahasa Indonesia akan menimbulkan kekacauan berbahasa.

Bagaimana cara yang efektif untuk membantu memperlancar proses pembelajaran BIPA? Pertanyaan tersebut mengacu pada prinsip, strategi, metode, teknik dan media pembelajaran BIPA. Prinsip pembelajaran yang perlu diperhatikan misalnya pertimbangan lintas budaya pembelajar dan pengajarnya, proporsi materi keterampilan dan nonketerampilan, kateristik pembelajar, tujuan pembelajar belajar 
BIPA. Sedangkan strategi pembelajarannya adalah heuristic, yaitu proses mengaktifkan pembelajar, pembelajar aktif dan mandiri dalam mencari dan menemukan prinsip dan konsep yang mereka butuhkan dan crosslingual (antarbangsa), yaitu B1-nya digunakan sebagai sistem rujukan, ada perbandingan antara B1 dan B2-nya.

\section{KESIMPULAN}

Ada kecenderungan peningkatan jumlah pembelajar BIPA di dalam negeri dan luar negeri. Mereka ingin menjadi bilingual atau multilingual dengan bahasa Indonesia sebagai bahasa kedua atau ketiganya. Proses pembelajaran BIPA dapat memanfaatkan konsep bilingualism, seperti konsep pemerolehan dan pembelajaran, konsep monitoring dan konsep saringan afektif. Sedangkan pengajar BIPA perlu memiliki kompetensi linguistik, selain kompetensi pedagogi dan kompetensi komunikasi, termasuk komunikasi antarbudaya.

Teori yang bisa menjadi kerangka acuan bagi pengajar atau fasilitator proses pembelajaran BIPA adalah teori pemerolehan dan teori akulturasi. Prinsip pembelajaran yang perlu diperhatikan, di antaranya tujuan penutur asing belajar bahasa Indonesia, garadasi kesulitan bahan ajar, variasi bahan ajar, konteks, dan integrasi bahan ajarnya. Sedangkan prinsip-prinsip pembelajan BIPA yang perlu diperhatikan misalnya, aspek lintas budaya pembelajar dan budaya masyarakat bahasa target, karakteristik pembelajar sebagai orang dewasa, bukan anak-anak. 
119 - Konsep Bilingualisme dan Pembelajaran Bahasa Indonesia...................

\section{DAFTAR PUSTAKA}

Hamied, Fuad Abdul. 1989. Keterpelajaran dalam Konteks Pemerolehan Bahasa. Dalam PELLBA 2. Lembaga Bahasa Unika Atma Jaya Jakarta. Yogyakarta: Kanisius.

Kridalaksana, Harimurti. 1984. Kamus Linguistik. Jakarta: PT. Gramedia

Nababan, Sri Utari Subyakto. 1992. Psikolingistik suatu Pengantar. Jakarta: Pt. Gramedia.

Rivai, Ovi Soviaty dkk. 2010. Pemetaan Pengajaran Bahasa Indonesia bagi Penutur Asing BIPA) di Asia. Pusat bahasa, Jalan Daksinapati Barat IV, Rawamangun, Jakarta. 